\title{
The Protective Effect of Curcumin on lonizing Radiation-induced Cataractogenesis in Rats
}

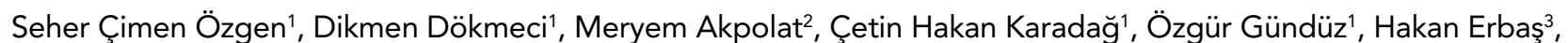
Ömer Benian ${ }^{4}$, Cem Uzal ${ }^{5}$, Fatma Nesrin Turan ${ }^{6}$

${ }^{1}$ Department of Pharmacology, Faculty of Medicine, Trakya University, Edirne, Turkey

${ }^{2}$ Department of Histology and Embryology, Faculty of Medicine, Trakya University, Edirne, Turkey

${ }^{3}$ Department of Biochemistry, Faculty of Medicine, Trakya University, Edirne, Turkey

${ }^{4}$ Department of Ophtalmology, Faculty of Medicine, Trakya University, Edirne, Turkey

${ }^{5}$ Department of Radiation Oncology, Faculty of Medicine, Trakya University, , Edirne, Turkey

${ }^{6}$ Department of Biostatistics, Faculty of Medicine, Trakya University, Edirne, Turkey

\begin{abstract}
Objective: The aim of the study was to determine the protective effect of curcumin against ionizing radiation-induced cataract in the lens of rats.

Material and Methods: Rats were divided into six groups. Group 1: Control, Group 2: Dimethyl sulfoxide (DMSO), Group 3: DMSO+curcumin, Group 4: Irradiation, Group 5: Irradiation+DMSO, Group 6: Irradiation+DMSO+curcumin. A 15 Gy total dose was given to 4, 5, 6 groups for radiation damage. Curcumin $(100 \mathrm{mg} / \mathrm{kg})$ was dissolved in DMSO and given by intragastric intubation for 28 days. At the end of the experiment, lenses were graded and enucleated. The lenticular activity of the antioxidant enzymes, total antioxidant and glutathione peroxidase (GSH-Px), and the malondialdehyde (MDA)
\end{abstract} were measured.

Results: $100 \%$ Cataract was seen in the irradiation group. Cataract rate fell to $40 \%$ and was limited at grade 1 and 2 in the curcumin group. In the irradiation group, antioxidant enzyme levels were decreased, MDA levels were increased. There was an increase in antioxidant enzyme levels and a significant decrease in MDA in the group which was given curcumin.

Conclusion: Curcumin has antioxidant and radioprotective properties and is likely to be a valuable agent for protection against ionizing radiation. Hence, it may be used as an antioxidant and radioprotector against radiation-induced cataractogenesis.

Key Words: Cataract, curcumin, ionizing radiation, lipid peroxidation, oxidative stress, radioprotective

\section{Introduction}

Cataract results from loss of transparency of the normal crystalline eye lens, and it is the major cause of blindness. Because pharmocological treatment of human cataract has so far not been achieved, surgery is the only effective treatment. Many risk factors are associated with the pathogenesis of cataract, such as aging, diabetes, environmental factors, sunlight, nutritional deficiencies or inadequacies (1). In addition, excessive free radical generation leading to oxidative stress has been identified as a major triggering factor for cataract formation and it is likely to be involved in the pathogenesis of radiation-induced retinal damage (2).

Radiation therapy plays an important role in the curative and palliative treatment of malignant diseases. Exposure of the body to ionizing radiation produces the reactive oxygen species (ROS) that damages proteins, lipids and nucleic acids. Because of the lipid component in the membrane, lipid peroxidation is reported to be particularly susceptible to radiation damage. In addition, cell lipid peroxidation is related to radiation-induced cell death, changes in membrane fluidity, and in the activities of some membrane enzymes (3). Furthermore, it has been shown that irradiation causes a marked change in the plasma total antioxidant capacity, and total body irradiation is known to cause a pronounced decrease in antioxidant capacity and an excessive increase in oxidant stress (4). Mammals are endowed with antioxidant defense systems that scavenge and minimize the formation of ROS. However, these systems are not always fully operative. Therefore, diet derived antioxidants become particularly important in diminishing cumulative oxidative damage, and a number of dietary antioxidants have been reported to decrease free radical attack on biomolecules (5).

Curcumin has antioxidant, radioprotective, antibacterial, antifungal, antiviral, antiinflammatory, antiproliferative, proapoptotic and antiatherosclerotic effects, exerting medicinal benefits for arthritis, allergy, asthma, inflammatory bowel disease, nephrotoxicity, psoriasis, diabetes, Alzheimer's disease, multiple sclerosis, cancer, neurodegenerative and cardiovascular disease (6-9). It is known that curcumin prevents 
the formation of ROS and scavenges free radicals and it protects cells from peroxidative stress. Curcumin not only exhibits antioxidative and free radical scavenging proeorties, but also enhances the activities of antioxidant enzymes such as superoxide dismutase (SOD), catalase, and glutathione peroxidase (GSH-Px) $(6,10)$. It is therefore possible that curcumin could scavenge free radicals and produce beneficial effects against radiation damage. To our knowledge, the role of curcumin on irradiation-induced cataract is undefined. Hence, we hypothesized that curcumin, because of its antioxidative effects, may be useful in preventing ionizing radiation cataractogenesis.

\section{Material and Methods}

This experimental study was conducted in accordance with the principles and procedures of the National Institutes for Health Guide for the Care and Use of Laboratory Animals. In addition, the experimental protocol was approved by the Ethical Committee of Trakya University.

\section{Animals}

A total of forty eight 8-10 weeks of age male Sprague Dawley rats $(200 \pm 30 \mathrm{~g})$ were used in this study. The experimental animals were housed at $22 \pm 1^{\circ} \mathrm{C}$ under a $12 \mathrm{~h}$ light/12 $\mathrm{h}$ dark cycle and had free access to a standard pellet diet for rats and to tap water. The administered concentration of the curcumin (Sigma, St.Louis, MO, USA) used in this study was dissolved in DMSO (Sigma, St.Louis, MO, USA).

\section{Experimental design}

Rats were divided into six groups with 8 animals in each: control, dimethyl sulfoxide (DMSO), DMSO+curcumin, irradiation, irradiation+DMSO, irradiation+DMSO+curcumin. Group 1 did not receive curcumin, irradiation or DMSO (control) but received sham irradiation. Group 2 did not receive curcumin or irradiation but $10 \mathrm{~mL} / \mathrm{kg}$ DMSO was given by intra gastric intubation. Group 3 were given curcumin (100 mg/kg) (10) dissolved in DMSO by intragastric intubation. Group 4 received total cranium 15 Gy of gamma irradiation. Group 5 received total cranium irradiation plus DMSO. Group 6 received total cranium irradiation plus curcumin dissolved in DMSO. The groups given DMSO or curcumin dissolved in DMSO were started one day before irradiation, with a total 28 days of the study.

Prior to total cranium radiotherapy, the rats were anesthetized with an intraperitoneal injection of ketamine $90 \mathrm{mg} / \mathrm{kg}$ (Ketalar, Eczacıbası, Istanbul, Turkey) and xylazine $10 \mathrm{mg} / \mathrm{kg}$ (Rompun, Bayer, Istanbul, Turkey) and placed on a plexiglas tray in the prone position. While the rats in the control, DMSO and DMSO+curcumin groups received sham irradiation, the rats in the irradiation, irradiation +DMSO and the irradiation +curcumin groups were irradiated using a cobalt 60 teletherapy instrument (Cirus, Cis-Bio Int-France) from a source-tosurface distance of $80 \mathrm{~cm}$ by $5 \times 5 \mathrm{~cm}$ anterior fields with a total $15 \mathrm{~Gy}$ to the total cranium. The animals were irradiated with a total $15 \mathrm{~Gy}$. To increase the lens dose to the maximum, a wax bolus material, $0.5 \mathrm{~cm}$ thick, was placed on the rats' eyes. The central axis dose was calculated at a depth of $0.5 \mathrm{~cm}$. the dose rate was $0.59 \mathrm{~Gy} / \mathrm{min}(11)$.

\section{Determination of clinical cataract}

In this study, the lens opacities classification system, version III was used in the cataract classification. The lenses were graded by slit-lamp biomicroscopy (Top Con SL-7F. TopCon Corp, Tokyo-Japan). At the beginning and at the last day of the experiment, we took photographs (TopCon MT-10) of all rats, and graded. Grade 0: normal clear lens; grade 1: initial sign of posterior subcapsular or nuclear opacity involving tiny scatters; grade 2: slight nuclear opacity involving tiny scatters; grade 3: diffuse nuclear opacity with cortical scattering; grade 4: partial nuclear opacity. At the beginning all lenses were examined as having no cataract (Grade 0$)(12,13)$.

\section{Biochemical analysis}

At the end of the study, the animals were anaesthetized by intraperitoneal injection of ketamine $(90 \mathrm{mg} / \mathrm{kg})$ and xylazine $(10 \mathrm{mg} / \mathrm{kg})$. Their eyes were enucleated, and the lenses were dissected out immediately. Lenses were rinsed in icecold distilled water, and immediately placed in three times their volume of cold $1.15 \% \mathrm{KCl}(5 \mathrm{~mL})$ containing $0.2 \%$ Triton $\mathrm{X}-100$. Lenses were homogenized by a homogenizer (Miccra RT D-1) for $10 \mathrm{~s}$ at the first speed level. Then, the homogenate was centrifuged at $3000 \mathrm{rpm}$ for $10 \mathrm{~min}$ at $4^{\circ} \mathrm{C}$. The supernatant was stored at $-80^{\circ} \mathrm{C}$ for biochemical analyses. The activities of GSH-Px and total antioxidant enzymes and the MDA level were determined in these supernatants spectrophotometrically (Unico 2800 UV/VIS Spectrophotometer). The MDA level was expressed as $\mu \mathrm{Mol} / \mathrm{mg}$ protein. The activities of total antioxidant and GSH-Px enzymes were expressed as $\mathrm{mM} / \mathrm{mg}$ protein of lens sediment (12).

\section{Statistical analysis}

All statistical analyses were carried out using SPSS statistical software. The results are presented as the mean \pm standard deviations. Enzyme parameters and lipid peroxidation levels of matched experimental and control pairs were analyzed with the Kolmogorov Smirnov test. When there was a significant difference among the groups, one way ANOVA and post-hoc Tukey HSD test used. $P$ values of less than 0.05 were considered statistically significant.

\section{Results}

The animals were weighed at the beginning and end of the experiment. No difference was found in the groups of the irradiated rats according to weight (data not shown). The grades of lens by slit-lamp biomicroscopy are presented in Table 1. At the beginning of the experiment, all of the lenses in each group had no cataract (Figure 1) and were graded as 0 . At the end of the experiment, none of the lenses in any of the groups were graded as 4.

At the end of the experiment; all of the lenses in control group, DMSO group and curcumin group had no cataract (Figure 2) and was graded as 0 . In the irradiation group, 2 rats (25\%) had cataract at grade 1; 4 rats $(50 \%)$ had cataract at grade 2 ; and 2 rats (25\%) had cataract at grade 3 . In the irradiation+DMSO group, 3 rats $(50 \%)$ had cataract at grade $2 ; 3$ rats (50\%) had cataract at grade 3 . In the irradiation+DMSO+curcumin group, 4 rats $(57 \%)$ had no cata- 
Table 1. Cataract development

\begin{tabular}{|lccccc|}
\hline & Grade 0 (\%) & Grade 1 (\%) & Grade 2 (\%) & Grade 3 (\%) & Total (\%) \\
\hline Grup 1 (Control) & $6(100)$ & - & - & - & $6(100)$ \\
Grup 2 (DMSO) & $7(100)$ & - & - & - & $7(100)$ \\
Grup 3 (DMSO+Curcumin) & $7(100)$ & - & - & - & $7(100)$ \\
Grup 4 (RT) & - & $2(25)$ & $4(50)$ & $2(25)$ & $8(100)$ \\
Grup 5 (RT+DMSO) & - & - & $3(50)$ & $3(50)$ & $6(100)$ \\
Grup 6 (RT+DMSO+curcumin) & $4(57.1)$ & $1(14.3)$ & $2(28.6)$ & - & $7(100)$ \\
\hline
\end{tabular}

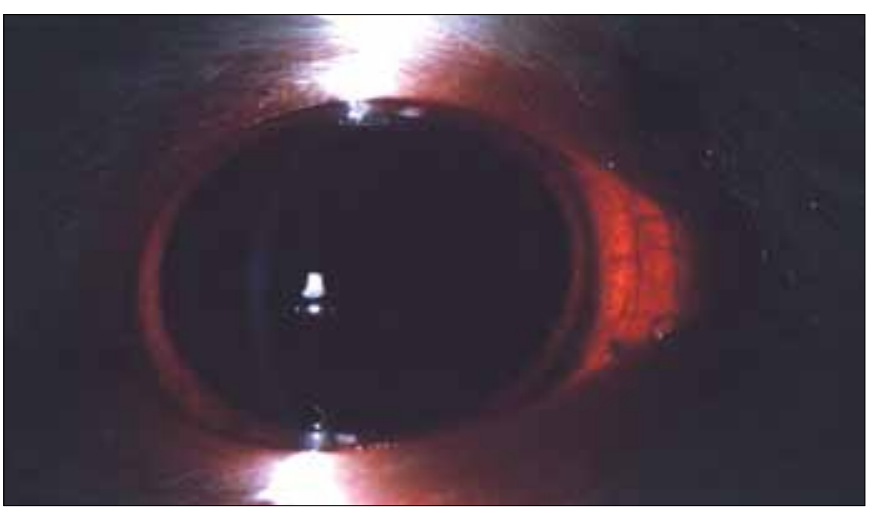

Figure 1. The first day of the study, no cataract in all of the groups

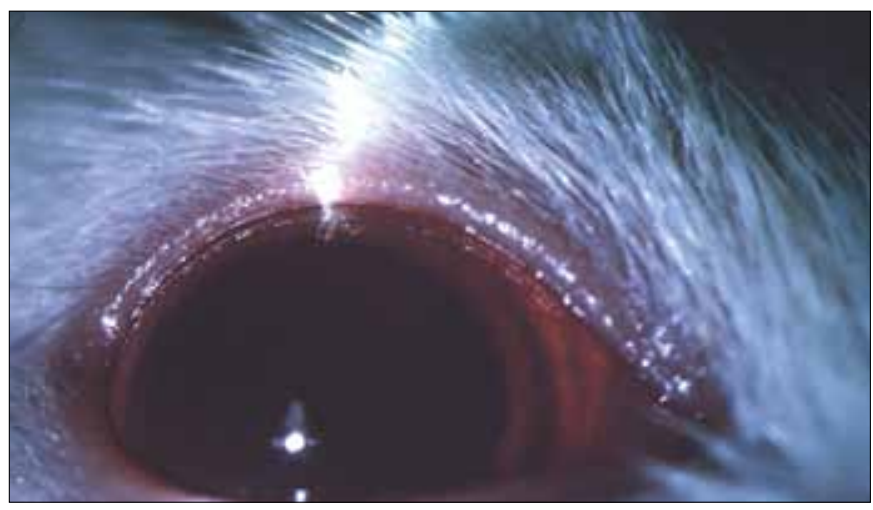

Figure 2. The last day of the study, no cataract in DMSO and DMSO+curcumin group

ract at grade $0 ; 1$ rat (14.3\%) had cataract at grade $1 ; 2$ rats (28.6\%) had cataract at grade 2 .

Cataract develepment was detectable in 8 rats $(100 \%)$ in the irradiation group (Figure 3), but the cataract development was detectable in 4 rats (50\%) in the irradiation+DMSO+curcumin group (Figure 4). Compared with those in the irradiation group, a significant reduction in cataract formation was observed in the irradiation+DMSO+curcumin group.

The activity of MDA, total antioxidant and GSH-Px enzymes are all presented in Figure 5-7, respectively. Compared with the control group, irradiation significantly increased the MDA levels as a major degradation product of lipid peroxidatin $(p<0.05)$. Irradiation also significantly decreased the total antioxidant enzymes $(p<0.05)$. Compared with the irradiation+DMSO and irradiation+DMSO+curcumin group, irradiation significantly

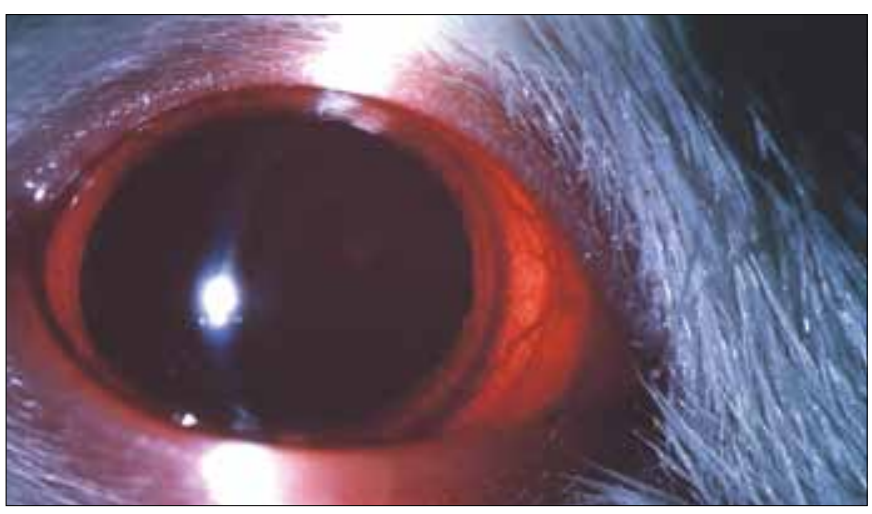

Figure 3. The last day of the study, in group 4 (irradiation); cataract developed in all rats

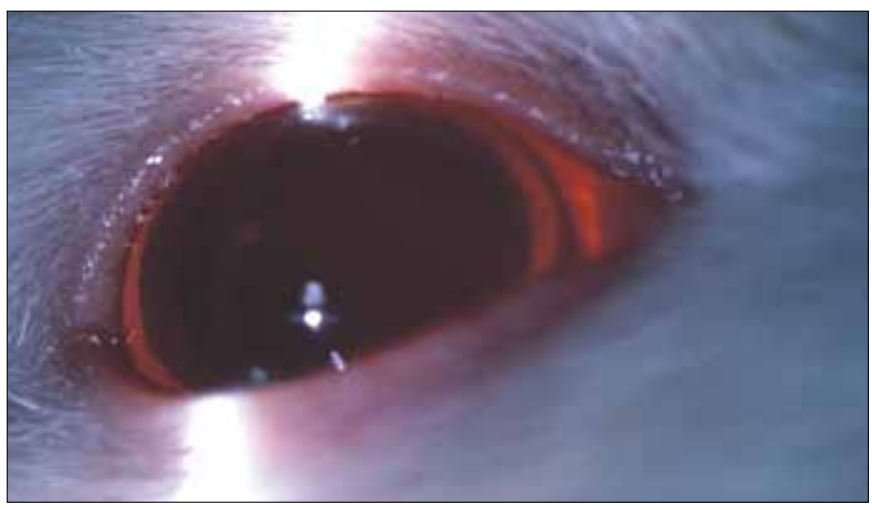

Figure 4. The last day of the study, in group 6 (irradiation+DMSO+curcumin); there was no cataract in 4 animals out of seven

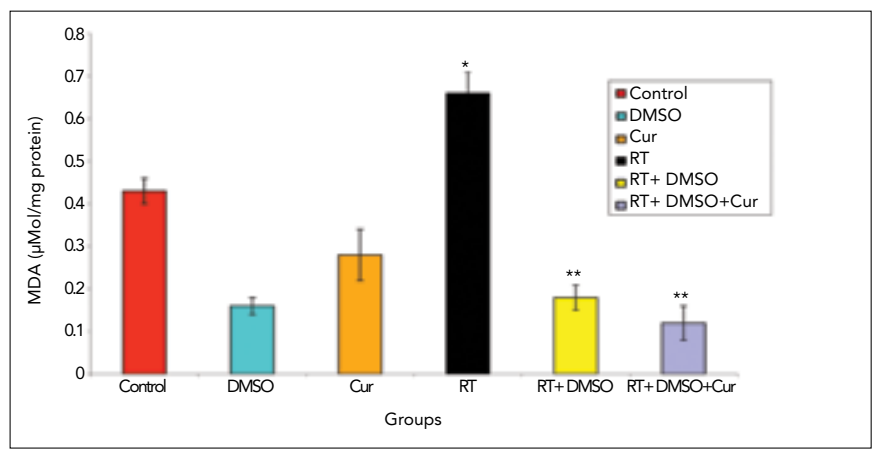

Figure 5. MDA levels

${ }^{*} p<0.05$ vs. control group on day 28

$\star \star p<0.05$ vs. irradiation group on day 28 


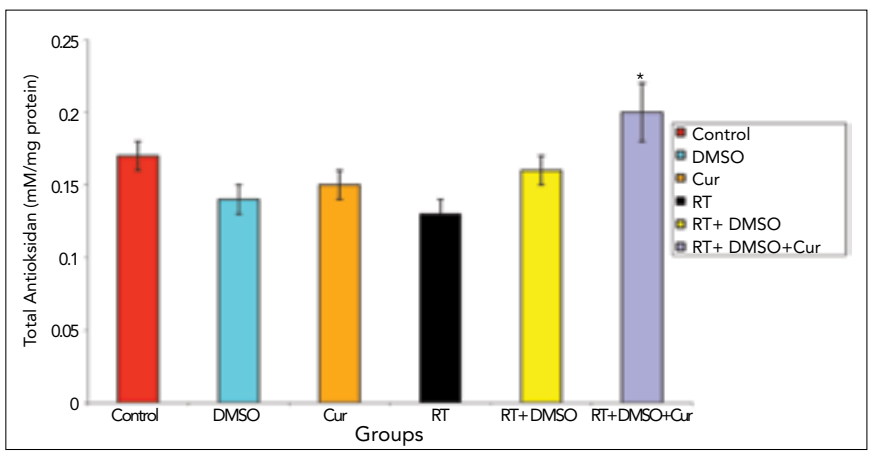

Figure 6. Total antioxidant levels ${ }^{*} p<0.05$ vs. irradiation group on day 28

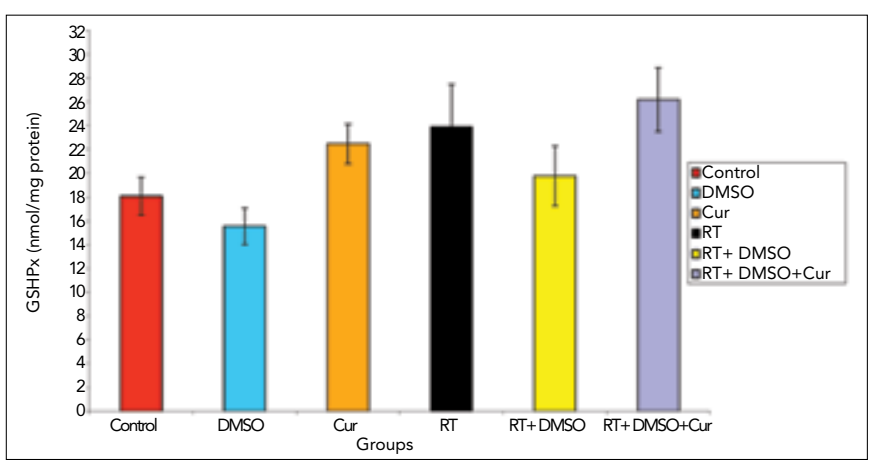

Figure 7. GSH-Px levels

increased the MDA levels $(p<0.05)$. MDA levels were significantly decreased in the groups which had been given DMSO or DMSO+curcumin after irradiation $(p<0.05)$.

Compared with the other groups, the level of total antioxidant were significantly decreased in the irradiation group, and significantly increased in the group that had been given curcumin after irradiation $(\mathrm{p}<0.05)$.

The activity of GSH-Px, which indicated the generation of oxidative stress and an early protective response to oxidative damage, increased in the irradiation+curcumin group, compared with the irradiation groups However, this was not statistically significant.

\section{Discussion}

Cataract is one of the major causes of preventable blindness in the world, although surgery is the only treatment method for human cataract. There is no accepted pharmacological agent at present to regress the opacification. Though the exact mechanism of cataract formation is still unclear, many studies used different models of cataract in order to target critical steps to stop or retard this process $(14,15)$. Among various models, the diabetes, selenite and radiation -induced cataract models are the most commonly used experimental models.

The lens of the eye is recognized as one of the most radiosensitive tissues in the human body, and it is known that ionizing radiation on the lens of the eye can produce a progressive cataract. Although much work has been carried out in this area, the exact mechanisms of radiation-induced cataractogenesis are still not fully understood. Radiation-induced cell damage involves generating ROS in the cell. Oxidative stress is likely to be involved in the pathogenesis of radiationinduced retinal damage. The lens includes defense mechanisms as in other tissues that may protect it from the effects of oxidation. A decrease in the antioxidant defenses increases lens oxidation and this could be responsible for the development of cataract $(11,16,17)$.

There is an increasing interest in developing suitable antioxidant nutrients, both of synthetic and plant origin, that could be effective in delaying or preventing the formation of cataract. Several studies have suggested that intake of antioxidant-rich foods may slow the progression of cataract. Therefore, to date, a number of antioxidant chemicals and drugs such as L-carnitine, acetyl-L-carnitine, lycopene, melatonin, resveratrol, $\alpha$-lipoic acid, Ginkgo biloba, $\alpha$-tocopherol, $\mathrm{N}$-acetylcysteine, pyruvate and verapamil have been used to prevent experimental cataract in the lens $(11,12,14,15,18$ $25)$. They were found to be effective in preventing cataract, but none have been implemented in clinical practice. All these studies showed the role of oxidative damage in the pathogenesis of cataracts and also the protective effect of antioxidants. The current study appears to be the first in the literature showing the antioxidant and radioprotective effect of curcumin in radiation-induced experimental cataract.

Curcumin, a natural product present in Curcuma longa or turmeric, has been shown to have antioxidant activity against free radicals both in vitro and in vivo, and is effective in preventing oxidative stress (6-10). In the previous studies, it was reported that curcumin has a radioprotective effect $(6,7,10,26)$. It was demonstrated that curcumin protected radiation-induced breast tumor, and curcumin and the tetrahydrocurcumin, a metabolite of curcumin, were observed to decrease the radiation-induced lipid peroxidation in rat liver microsomes $(27,28)$. Indeed, experimental studies with diabetic animals suggested that curcumin can suppress cataract development, promote wound healing, and lower blood lipids and glucose levels (29). Jagetia et al. $(6,10)$ showed that radiation-induced delay in wound healing is decreased with the antioxidant effects of curcumin.

Suryanarayana et al. (30) investigated the effects of curcumin in the galactose-induced cataract model with two levels of curcumin, $0.002 \%$ and $0.01 \%$, in the diet. Although curcumin delayed the onset of cataract at both levels, maturation was delayed by $0.002 \%$ curcumin, but not by $0.01 \%$. The maturation was faster with $0.01 \%$ curcumin. Biochemical analyses demonstrated that curcumin at the $0.002 \%$ level appeared to exert antioxidant and antiglycating effects, as it inhibited lipid peroxidation. Later, Suryanarayana et al. (31) investigated the effect of curcumin and its source turmeric, on streptozotocininduced diabetic cataract in rats. In this study, both curcumin and turmeric did not prevent streptozotocin-induced hyperglycemia, but delayed the progression and maturation of cataract.

Kumar et al. (32) investigated whether curcumin modulates the chaperone activity of $\alpha$-crystallin in streptozotosin-induced diabetic rat lenses. They reported that in streptozotosininduced diabetic cataract, $\alpha$-crystallin exhibited diminished chaperone activity, which was prevented by dietary curcumin. Awasthi et al. (33) showed that curcumin protects against 4-hy- 
droxy-2-trans-nonenal-induced cataract formation in rat lenses. The authors suggested that curcumin may be an effective protective agent against cataractogenesis induced by lipid peroxidation, and this protective effect may be mediated through the induction of glutathione s-transferase isozyme. They demonstrated that curcumin induced the glutathione linked detoxification pathway activates a protective mechanism associated with GSH and provides it as a free radical scavenger. However in our study, curcumin decreased the maturation of cataract clinically, decreased MDA levels, but there was no significant difference in the GSH-Px levels, which was suprising . Administration of naphthalene is known to cause cataract formation experimentally. Oxidative stress has been implicated in the mechanism of this cataract model. Pandya et al. (34) demonstrated also that oxidative stress triggers the maturation of cataract and $0.005 \%$ level of curcumin significantly reduced the cataract formation in naphthalene-induced cataract.

Manikandan et al. (35) investigated the anticataractogenic effect of curcumin against selenium-induced oxidative stress in the lens of rat pups in vitro and in vivo (36). They showed that curcumin prevented cataractogenesis by reducing the intensity of lipid peroxidation, enhancing the antioxidant enzyme activities, and also by inhibiting free radical generation. In another study, curcumin also prevented selenium-induced oxidative stress leading to activation of $\mathrm{Ca}^{+2}$ ATPase and free radical-mediated $\mathrm{Ca}^{+2}$ accummulation in the eye lens (37). Further, Manikandan et al. (1) has also studied whether curcumin can ameliorate the elevated expression of both $\alpha \mathrm{A}$ - and $\alpha \mathrm{B}$ crystallin and heat shock protein 70 in the eye lens of rat pups exposed to selenium. Interestingly, curcumin led to a decrease in the expression of these in the eye lens.

Global tissue damage due to oxygen-derived free radicals has been implicated in several pathological processes including exposure to ionizing radiation. The damaging effect of ionizing radiation on living cells is predominantly due to ROS, and there are two available antioxidant strategies in oxidative stress. In the first, ROS are removed using specific enzymes such as SOD and GSH-Px, either by administration of these enzymes or by increasing their in vitro activities. Since biological antioxidants inactivate free radicals and their products, the enzymes involved in the metabolism of ROS are expected to play an important role in the radiosensitivity of cells. Hence, chemical repair may be provided by radioprotective compounds present during exposure to ionizing radiation (38). Natural antioxidants, and especially dietary polyphenols, have been reported to decrease free radicals and have rapidly gained attention as viable candidates for clinical testing in cataractogenesis (39). Currently, there are no highly effective radioprotective drugs available for reducing the ocular damage from medical or occupation-related radiation exposure.

Many studies have documented oxidative stress associated with irradiation-induced cataractogenesis. L-carnitine, melatonin, Ginkgo biloba, vitamin E, estrogen, metalloporphyrin and verapamil protected irradiation-induced cataract development by virtue of their antioxidant properties $(2,11,12,16,17,19$, $22,23,40,41)$. The investigators measured MDA and the antioxidant enzyme levels such as SOD, catalase, total antioxidant in the lens tissues and graded the lens opacification. Similar to the above studies, in our study we also evaluated MDA, GSH-
Px and total antioxidant levels in lens tissue. Cataract rate decreased with antioxidants in these studies and these rates were similar to our results. At the end of our study, irradiated lenses had higher grades of cataract than those for the other groups, and the degree of cataract was lower in curcumin-treated rats. Lipid peroxidation has been linked to cataractogenesis in animal models. MDA, a stable end-product of lipid peroxidation generated by ROS, is usually used as a good indicator of the degree of lipid peroxidation. MDA levels in lens tissue increases after irradiation-induced cataract. In the present study, we found that the MDA levels in the rat lens in the irradiation group were significantly higher than that in those of the control group. MDA levels were significantly decreased in the groups which had been given curcumin after irradiation. Irradiation also significantly decreased the total antioxidant enzyme levels. Compared with the other groups, the level of total antioxidant levels were significantly increased in the group given curcumin after irradiation. This is consistent with the hypothesis that ionizing irradiation generates oxidative stress. In the present paper, for the first time we showed that curcumin prevents cataract in this model of cataract. The activity of GSH-Px, which indicates the generation of oxidative stress and an early protective response to oxidative damage, increased in the irradiation+curcumin group, compared to the irradiation group, but this was not statistically significant. However, various studies about the level of GSH-Px, $(12,17)$ have different conclusions. Different studies and also our study, reveals doubtsabout the effect of GSH-Px in the oxidative process.

\section{Conclusion}

We focus on a natural compound (nutraceutical) curcumin and their abilities to act as antioxidants and cell protectants in cataract. Although several antioxidants have been used for protecting irradiation-induced cataract to date, there has been no research into the role of curcumin in irradiation cataractogenesis. To our knowledge, our results provide the first evidence of the role of curcumin in the pathogenesis of irradiation-induced cataract model. Our results suggest that curcumin has a protective effect in this injury. By the same token, the protective activity of curcumin observed in the current paper can possibly be mediated through its well-known antioxidant potential. Hence, we propose that curcumin may be a novel approach to therapy for cataract. However, further animal and human studies are required to elucidate the mechanism by which curcumin offers these protective functions.

\section{Acknowledgements}

This study was supported by the Trakya University Scientific Research Project Unit (TUBAP), Edirne, Turkey.

\section{Conflict of Interest}

No conflict of interest was declared by the authors.

\section{References}

1. Manikandan R, Beulaja M, Thiagarajan R, Arumugam M. Effect of curcumin on the modulation of $\alpha A$ - and $\alpha B$-crystallin and heat shock protein 70 in selenium-induced cataractogenesis in Wistar rat pups. Mol Vis 2011;17:388-94. 
2. Mao XW, Crapo JD, Mekonnen T, Lindsey N, Martinez P, Gridley DS, Slater JM. Radioprotective effect of a metalloporphyrin compound in rat eye model. Curr Eye Res 2009;34:62-72. [CrossRef]

3. Riley PA. Free radicals in biology: oxidative stress and the effects of ionizing radiation. Int J Radiat Biol 1994;65:27-33. [CrossRef]

4. Akpolat M, Topcu-Tarladacalisir Y, Dokmeci D, Turan FN, Uzal MC. Protective effects of ibuprofen and L-carnitine against whole body gamma irradiation-induced duodenal mucosal injury. Balkan Med J 2011;28:80-5.

5. Varma SD, Kovtun S, Hegde KR. Role of ultraviolet irradiation and oxidative stress in cataract formation-medical prevention by nutritional antioxidants and metabolic agonists. Eye Contact Lens 2011;37:233-45. [CrossRef]

6. Jagetia GC, Rajanikant GK. Effect of curcumin on radiationimpaired healing of excisional wounds in mice. J Wound Care 2004;13:107-9.

7. Jagetia GC. Radioprotection and radiosensitization by curcumin. Adv Exp Med Biol 2007;595:301-20. [CrossRef]

8. Jagetia GC, Aggarwal BB. "Spicing up" of the immune system by curcumin. J Clin Immunol 2007;27:19-35. [CrossRef]

9. Zhou H, Beevers CS, Huang S. The targets of curcumin. Curr Drug Targets 2011;12:332-47. [CrossRef]

10. Jagetia GC, Rajanikant GK. Acceleration of wound repair by curcumin in the excision wound of mice exposed to different doses of fractionated $\gamma$ radiation. Int Wound J 2012;9:76-92. [CrossRef]

11. Kocer I, Taysi S, Ertekin MV, Karslioglu I, Gepdiremen A, Sezen $O$, et al. The effect of L-carnitine in the prevention of ionizing radiation-induced cataracts: a rat model. Graefes Arch Clin Exp Ophthalmol 2007;245:588-94. [CrossRef]

12. Ertekin MV, Kocer I, Karslioglu I, Taysi S, Gepdiremen A, Sezen O, et al. Effects of oral Ginkgo biloba supplementation on cataract formation and oxidative stress occurring in lenses of rats exposed to total cranium radiotherapy. Jpn J Ophthalmol 2004;48:499-502. [CrossRef]

13. Chylack LT Jr, Ransil BJ, White O. Classification of human senile cataractous change by the American Cooperative Cataract Research Group (CCRG) method: III. The association of nuclear color (sclerosis) with extent of cataract formation, age, and visual acuity. Invest Ophthalmol Vis Sci 1984;25:174-80.

14. Gupta SK, Trivedi D, Srivastava S, Joshi S, Halder N, Verma SD. Lycopene attenuates oxidative stress induced experimental cataract development: an in vitro and in vivo study. Nutrition 2003;19:794-9. [CrossRef]

15. Hegde K, Kovtun S, Varma S. Prevention of cataract in diabetic mice by topical pyruvate. Clin Ophthalmol 2011;5:1141-5.

16. Karslioglu I, Ertekin MV, Koçer I, Taysi S, Sezen O, Gepdiremen $A$, et al. Protective role of intramuscularly administered vitamin $\mathrm{E}$ on the levels of lipid peroxidation and the activities of antioxidant enzymes in the lens of rats made cataractous with gammairradiation. Eur J Ophthalmol 2004;14:478-85.

17. Karslioglu I, Ertekin MV, Taysi S, Koçer I, Sezen O, Gepdiremen A, et al. Radioprotective effects of melatonin on radiation-induced cataract. J Radiat Res (Tokyo) 2005;46:277-82. [CrossRef]

18. Elanchezhian R, Sakthivel M, Geraldine P, Thomas PA. Regulatory effect of acetyl-I-carnitine on expression of lenticular antioxidant and apoptotic genes in selenite-induced cataract. Chem Biol Interact 2010;184:346-51. [CrossRef]

19. Taysi S, Memisogullari R, Koc M, Yazici AT, Aslankurt M, Gumustekin $\mathrm{K}$, et al. Melatonin reduces oxidative stress in the rat lens due to radiation-induced oxidative injury. Int J Radiat Biol 2008;84:803-8. [CrossRef]

20. Li G, Luna C, Navarro ID, Epstein DL, Huang W, Gonzalez P, et al. Resveratrol prevention of oxidative stress damage to lens epithelial cell cultures is mediated by forkhead box $\mathrm{O}$ activity. Invest Ophthalmol Vis Sci 2011;52:4395-401. [CrossRef]

21. Chen Y, Yi L, Yan G, Fang Y, Jang Y, Wu X, et al. alpha-Lipoic acid alters post-translational modifications and protects the chaperone activity of lens alpha-crystallin in naphthalene-induced cataract. Curr Eye Res 2010;35:620-30. [CrossRef]

22. Okumus S, Taysi S, Orkmez M, Saricicek E, Demir E, Adli M, et al. The effects of oral Ginkgo biloba supplementation on radia- tion-induced oxidative injury in the lens of rat. Pharmacogn Mag 2011;7:141-5. [CrossRef]

23. Wang J, Löfgren S, Dong X, Galichanin K, Söderberg PG. Dose-response relationship for $\alpha$-tocopherol prevention of ultraviolet radiation induced cataract in rat. Exp Eye Res 2011;93:91-7. [CrossRef]

24. Aydin B, Yagci R, Yilmaz FM, Erdurmus M, Karadağ R, Keskin U, et al. Prevention of selenite-induced cataractogenesis by N-acetylcysteine in rats. Curr Eye Res 2009;34:196-201. [CrossRef]

25. Ettl A, Daxer A, Göttinger W, Schmid E. Inhibition of experimental diabetic cataract by topical administration of RS-verapamil hydrochloride. Br J Ophthalmol 2004;88:44-7. [CrossRef]

26. Inano $\mathrm{H}$, Onoda $\mathrm{M}$. Radioprotective action of curcumin extracted from Curcuma longa LINN: inhibitory effect on formation of urinary 8-hydroxy-2'-deoxyguanosine, tumorigenesis, but not mortality, induced by gamma-ray irradiation. Int J Radiat Oncol Biol Phys 2002;53:735-43. [CrossRef]

27. Inano $H$, Onoda $M$, Inafuku $N$, Kubota $M$, Kamada $Y$, Osawa $T$, et al. Potent preventive action of curcumin on radiation-induced initiation of mammary tumorigenesis in rats. Carcinogenesis 2000;21:1835-41. [CrossRef]

28. Khopde SM, Priyadarsini KI, Guha SN, Satav JG, Venkatesan P, Rao MN. Inhibition of radiation-induced lipid peroxidation by tetrahydrocurcumin: possible mechanisms by pulse radiolysis. Biosci Biotechnol Biochem 2000;64:503-9. [CrossRef]

29. Jain SK, Rains J, Jones K. Effect of curcumin on protein glycosylation, lipid peroxidation, and oxygen radical generation in human red blood cells exposed to high glucose levels. Free Radic Biol Med 2006;41:92-6. [CrossRef]

30. Suryanarayana P, Krishnaswamy K, Reddy GB. Effect of curcumin on galactose-induced cataractogenesis in rats. Mol Vis 2003;9:223-30.

31. Suryanarayana $P$, Saraswat $M$, Mrudula T, Krishna TP, Krishnaswamy K, Reddy GB. Curcumin and turmeric delay streptozotocin-induced diabetic cataract in rats. Invest Ophthalmol Vis Sci 2005:46:2092-9. [CrossRef]

32. Kumar PA, Suryanarayana P, Reddy PY, Reddy GB. Modulation of alpha-crystallin chaperone activity in diabetic rat lens by curcumin. Mol Vis 2005;11:561-8.

33. Awasthi S, Srivatava SK, Piper JT, Singhal SS, Chaubey M, Awasthi YC. Curcumin protects against 4-hydroxy-2-trans-nonenal-induced cataract formation in rat lenses. Am J Clin Nutr 1996;64:761-6

34. Pandya U, Saini MK, Jin GF, Awasthi S, Godley BF, Awasthi YC. Dietary curcumin prevents ocular toxicity of naphthalene in rats. Toxicol Lett 2000;115:195-204. [CrossRef]

35. Manikandan R, Thiagarajan R, Beulaja S, Chindhu S, Mariammal $\mathrm{K}$, Sudhandiran G, et al. Anti-cataractogenic effect of curcumin and aminoguanidine against selenium-induced oxidative stress in the eye lens of Wistar rat pups: An in vitro study using isolated lens. Chem Biol Interact 2009;181:202-9. [CrossRef]

36. Manikandan R, Thiagarajan R, Beulaja S, Sudhandiran G, Arumugam M. Effect of curcumin on selenite-induced cataractogenesis in Wistar rat pups. Curr Eye Res 2010;35:122-9. [CrossRef]

37. Manikandan R, Thiagarajan R, Beulaja S, Sudhandiran G, Arumugam M. Curcumin prevents free radical-mediated cataractogenesis through modulations in lens calcium. Free Radic Biol Med 2010;48:483-92. [CrossRef]

38. Dokmeci D, Akpolat M, Aydogdu N, Uzal C, Turan FN. The modifying effect of ibuprofen on total body irradiation-induced elevation of oxidative reactions in male hamsters. Acta Med Biol 2004;52:67-72

39. Kelsey NA, Wilkins HM, Linseman DA. Nutraceutical antioxidants as novel neuroprotective agents. Molecules 2010;15:7792-814. [CrossRef]

40. Dynlacht JR, Valluri S, Lopez J, Greer F, Desrosiers C, CaperellGrant $A$, et al. Estrogen protects against radiation-induced cataractogenesis. Radiat Res 2008;170:758-64. [CrossRef]

41. Cengiz M, Gürkaynak M, Atahan IL, Kiliç K, Totan Y. The effect of verapamil in the prevention of radiation-induced cataract. Int J Radiat Oncol Biol Phys 1999;43:623-6. [CrossRef] 